\title{
Parental origin of WT1 mutations and mental retardation in WAGR syndrome
}

\begin{abstract}
Sir - In the March 1994 issue of Nature Genetics, Jinno et al. report the monoallelic expression of the $11 \mathrm{p} 13$ Wilms tumour gene, WT1, in tissue samples from two fetal brains ${ }^{1}$. They suggest that WT1 is important in brain development and that its differential expression may play a part in the presence or absence of mental retardation in patients with the WAGR (Wilms tumour/aniridia/ genitourinary anomalies/mental retardation) syndrome. Because of the observation of monoallelic expression of the maternally derived WT1 allele in some placentas, they suggest that it is also the maternal allele expressed in brain. They further predict that patients with maternally inherited $11 \mathrm{p} 13$ deletions encompassing the WT1 locus would be mentally retarded, whereas patients carrying deletions of the paternally derived chromosome would not display mental retardation since the paternal allele is normally inactive in brain. As support for this hypothesis, data is cited for two children with $11 \mathrm{p} 13$ deletions whom
\end{abstract}

we studied several years ago ${ }^{2}$.

In that study we determined the parental origin of de novo $11 \mathrm{p} 13$ germline deletions in eight patients. Of the eight, seven carried paternally derived deletions ${ }^{2}$. Clinical data were previously published for four patients. Of these four (all carrying paternally derived deletions) ${ }^{2}$, two patients (LCS120 and LCS144; see Table) were described as mentally retarded ${ }^{3,4}$, one (LCS036) was developmentally "unremarkable", and one (LCS134) showed "cognitive and linguistic functions in the average range, although his adaptive skills showed borderline delay" ${ }^{\prime \prime}$. In the latter case and other such questionable cases of mental retardation, borderline delay may not be a direct result of the deletion, but rather an indirect result of aniridia-related visual problems that lead secondarily to developmental delays.

Jinno etal.mention the two patients (LCS036 and LCS134) who carried paternally derived $11 \mathrm{p} 13$ deletions, but were not mentally retarded, to support their hypothesis. However,

\begin{tabular}{|c|c|c|c|c|c|}
\hline \multicolumn{6}{|c|}{ Table 1 Carriers of germline $11 \mathrm{p} 13$ deletions } \\
\hline Patient & $11 p$ deletion & Origin of deletion & Parental origin & $\begin{array}{l}\text { Mental } \\
\text { retardation }\end{array}$ & Ref. \\
\hline 1 (LCS120) & p12.8- p15.1 & de novo deletion & paternal & yes & 2,3 \\
\hline 2 (LCS144) & $\mathrm{p} 13.4-\mathrm{p} 14.3$ & de novo deletion & paternal & yes & 2,4 \\
\hline 3 (LCS036) & n.d. & de novo deletion & paternal & no & 2,5 \\
\hline $4(\operatorname{LCS} 134)$ & $\mathrm{p} 1304-\mathrm{p} 14.1$ & de novo deletion & paternal & no (?) & 2,6 \\
\hline $5(209942)$ & n.d. & $\begin{array}{l}\text { de novo WT1 } \\
\text { intragenic deletion }\end{array}$ & paternal & no & 8 \\
\hline 6 (LEV5) & $\mathrm{p} 13$ & $\begin{array}{l}\text { Inheritance of unbalanced } \\
\text { translocation chromosome }\end{array}$ & paternal & yes & 9 \\
\hline 7 & p13-14.1 & $\begin{array}{l}\text { Inheritance of unbalanced } \\
\text { translocation chromosome }\end{array}$ & maternal & yes & 10 \\
\hline $8^{b}$ & p11.3-p14 & $\begin{array}{l}\text { Inheritance of unbalanced } \\
\text { translocation chromosome }\end{array}$ & maternal & yes & 11 \\
\hline $9^{b}$ & p11.3-p14 & $\begin{array}{l}\text { Inheritance of unbalanced } \\
\text { translocation chromosome }\end{array}$ & maternal & yes & 11 \\
\hline $\begin{array}{l}10(\mathrm{TCH} \\
\text { No. } 544150)\end{array}$ & p12-p13 & $\begin{array}{l}\text { Inheritance of unbalanced } \\
\text { translocation chromosome }\end{array}$ & maternal & yes & 12 \\
\hline $11(165)$ & p11.2-p13 & de novo deletion & paternal $^{c}$ & no & 13,14 \\
\hline
\end{tabular}

two other patients (LCS120 and LCS144) in our study also carried paternally derived deletions and were definitely mentally retarded. Thus, our data do not support the idea that parental origin of the $11 \mathrm{p} 13$ deletion is related to mental retardation.

The table summarizes data on patients with germinal $11 \mathrm{p} 13$ deletions for whom parental origin of the deletion can be determined and mental development is reported. The first five sustained newly arisen $11 \mathrm{p} 13$ deletions, whereas patients 6-9 inherited unbalanced translocation chromosomes from parents who were balanced translocation carriers. The presence of mental retardation appears to be independent of parental origin of the $11 \mathrm{p} 13$ deletion: mental retardation is observed both in patients whose deletions are of paternal and of maternal origin. Interestingly, the $11 \mathrm{p} 13$ deletion in the patients with no salient mental retardation are generally smaller than the deletions observed in the patients with mental retardation. Patients LCS036 and 209942 carried cytogenetically undetectable deletions, the sizes of which are estimated to be $\sim 1 \mathrm{Mb}$ and $2-4 \mathrm{~kb}$, respectively ${ }^{7,8}$. These data suggest that deletion of a gene(s) in the region of the aniridia and WT1 genes is involved in the severe mental retardation observed in some $11 \mathrm{p} 13$ deletion patients. In summary, the existing data suggest that brain-specific imprinting of the WT1 locus and maternal (versus paternal) inheritance of $11 \mathrm{p} 13$ deletions are not responsible for the presence or absence of the mental retardation phenotype.

\section{Vicki Huff \\ Department of Experimental Pediatrics, University of Texas M.D. Anderson Cancer Center, Houston, Texas 77030, USA}

Jinno and Reeve reply - Huff cites two WAGR patients (LCS120 and LCS144) with mental retardation and paternal chromosome $11 \mathrm{p} 13$ deletions which would appear not to support our speculation that 